\title{
Hypothetical Journalism in MACOSA Experience: The Nation and its Internet Readership Status
}

\author{
Ndoma J. Brown Ph.D. \\ Department of Mass Communication, Faculty of Communication Technology, Cross River University of \\ Technology, Calabar, Cross River State - Nigeria, P.M.B. 1123.
}

\begin{abstract}
This research was aimed at establishing whether truly there is a benchmark for appreciation of news contents in The Nation hardcopy and its internet version, by extension equipping students of Mass Communication as campus ecclesiasts. The students of Mass Communication Department, Cross River University of Technology, Calabar Campus - formed the research population. The sampled media were selected using the "hat and draw method." The period under review was January, 2013 to June, 2013, and one hundred and fifty (150) students, were the sampled. Two research questions were presented; using questionnaire as the survey instrument in determining to what extent their news contents were preferable. It was experimented on 'Uses and Gratification' and 'Media Dependency' Theories revealing that the popular reading culture of the hardcopy by the students was $76.6 \%$, comparatively greater than the $16.7 \%$ of the online version users - due to availability of hardcopies and infeasible presence of internet facilities, lack of fund to sustain mobile browsing capacity. Readership frequencies for hardcopy and net versions were $55.3 \%$ and $38 \%$. And $6.7 \%$ were nonreaders of the two. The research made some major revelations in line with encouraging campus journalism; one of them was that Mass Communication students of CRUTECH, Calabar should improve their reading culture as in expanding their frontiers of knowledge and by so doing dilate some level of hypothesis in the campus journalism practice. In a splint of hope, the study, recommended that the school's library and Mass Communication resource room should be accorded internet facilities and contemporarily stocked print media publications. As to ignite the learning environment at minimal or no cost; 'Open Sesame' to the world as global village is accessible from a wider reading spectrum, this will go a long way in influencing campus journalistic crave. The road to Damascus is realized if only these revelations are not under-dogged, as envisaged in the paradigm shift of brain drain and resources to qualitative opportunities in neigbouring African countries.
\end{abstract}

Key words: brain drain, hypothetical journalism, MACOSA, media dependency, news content, popular culture, uses and gratification.

\section{Introduction}

Harris in Baran in his definition of culture narrows it into a sharper scope as the learned, socially acquired traditions and lifestyles of the members of a society, including their patterned, repetitive ways of thinking, feeling and acting, [1]. Culture in this regards, critically assessed in the readership mannerism amongst Nigerian students' reading habits is a way of life which is fast declining. Analyses of the diminishing standards in the 2013 results of West African School Certificate (WASC), National Examination Council (NECO) and pitiable of it all the alarming rate of failure in the admission entrances into tertiary institutions in Nigeria, which has become quite worrisome. Against this uprising, "Nigeria's House of Representatives' recent reactions trailed the mass failure of candidates in 2013: Unified Tertiary Matriculation Examination, (UTME), to some of the candidates' reliance on answers provided by fraudsters, other's claimed that the use of computer affected their performance. The summons became necessary due to series of complaints and protests by a cross section of Nigerians. The lawmakers added that the mass failure might not be unconnected with the introduction of computers for the exams, bearing in mind that most candidates, especially from Government Secondary Schools were not computer literates. The result of the examination as released by JAMB showed many students scoring below 150, out of the 400 marks, with only 10 scoring above 300". [2] (Daily Post, online).

Sequel to this ugly situation in Nigeria, "the Dean, School of Postgraduate Studies, Tai Solarin University of Education, Ijagun, Ogun State, Segun Ogunsaju, had expressed concern over the continued trend of mass failure of candidates in public examinations in the country. If this trend was not checked, the nation's search for socio-economic, political and academic development would be truncated. In a lecture titled, "Education and the Challenges of Students' Poor Performance in the National Examinations: The Public Outcry," the professor of Educational Management observed that since 2005, less than $35 \%$ of candidates who sat for public examinations, including the West African Senior Secondary Certificate Examinations, hardly obtained credit passes in five subjects - including English and Mathematics", [3] (The Punch, online). 
An aggrieved contention into this palpitating research emanated from the aforementioned issues and other nefarious claims that tantamount to robbing Nigeria of her glorious educational impacts in the globe. It is not hallucinatory; definitely, these sets of pupil are going to be the ones to occupy the different disciplines in our tertiary institutions. Truly, these large scaled inconveniences are by-products of relegated attitudes, ignorance of appreciating dignity, virtues and pride. Such characterization could be traceable to the ill-informed reading attitude, poor informative habits between our mass media and media audiences. It is in this condition that it is deemed incumbent to kit the upcoming Mass Communicator as a combat ready journalist. In this noble profession of information dissemination, one is supposed to be disposed to opportunities of sifting digestible media contents for consumption. The case of being would-be mass communication Ambassadors leave more to be desirous, placing the discipline as a diligent watchdog of a society, when provoked can sometimes bite - after conscientious barks. In the context of comparing notes for information in-terms of knowledge and development in recreating avidity in characterization for the citizenry and student, it is imperative to crosscheck issues with relevant theses.

\section{Hypothetical Journalism}

The researcher conceptualizes the presage of experiencing difficulties in representing a democratic practice of freedom of information in an embryonic setting. A conditionalized effort, where the homo-sapiens's variables are at variance with the unpredictable nature of determining qualitative news perception and reporting attitudes even in the midst of a-posteriori opportunities. In this experimental setting (the campus), insurmountable human forces, strategized as the individual's basic income and poor governmental presence will determine consumer's quest for news. This is a preemie created by shotgun wedding to institutionalize a comparative society, which if effectively manage will replicate an effective media oriented society from the vestigial traces of infantry - where efficacy is set into motion to coup-de-theatre the dissemination of information and news. Likable chances of generating information flow should be dependable on accessibility and comfortability of the 'prosumers' (producers and consumers, that is student-to-student journalism) of up-tothe minute reportorial. At the endpoint of effective communication, the well informed student should also influence his community in his reportorial skills, as eradicating hiccups in campus journalism practice. Instance of such an expected juvenile media news appreciating organisation is the Department of Mass Communication in Cross River University of Technology as an entity with pregnable results.

\section{Content of The Nation}

The same blood in the arteries of other newspapers and online house styles; runs in The Nation as a regularized publication containing news of events, advertising, informative and diverse features. The Nation as a general interest newspaper, typically publishing stories on locally, nationally and internationally politicized events, society, sports, opinion/editorials; Brown [4]. These items in The Nation are explicitly captured as:

3.1. News: The Nation's news contents are very expansive and cover a lot of ingredients on ethical, editorial and international news, providing a sound environment for foreign news. On the ranking of news coverage in The Nation as news medium; summarizes a good story as having the following characteristics: (1) an interesting central character who (2) faces a challenge or is caught up in a conflict and (3) whose situation changes as (4) action takes place in (5) an engaging setting. In all these, Itule and Anderson categorized news as any event possessing timeliness, proximity, conflict, eminence and prominence, consequence and impact, and finally should have a human interest touch [5].

3.2. Features: By definition of its title, a feature story is a factual write-up in creatively long, well researched and containing opinions of the writer or interviewees on burning issues at stake. The feature story is completely, not the news story. It is not hard-news like the news story. It has prose format and allows the writer some measures of exploration, Nwosu [6].

3.3. Advertising: Newspapers contain paid forms of non-personal communication about an organisation, product, service or idea by an identified sponsor with the intent to persuade or influence behaviour in the audience. It is the easiest source of generating revenue for the media outfits. This department controls the premium in the scale of information importance in the layout scheme.

3.4. Cartoons: Cartoons as instrument of communication can be noticed in the areas of its gradual, systematic and attitudinal change impacted between an individual and its immediate or distant environment. Cartoons are generally seen as the pigment of an artistic impression, cajoled from a potpourri of the artist's world of alleged hallucinations and imaginations, Brown et al. [7]. 


\section{Distinctive Contents of the online Nation}

The Nation as an online publication on the web has distinctive characteristics likened to any online journalism. Anim [8] critically identified these characteristics as:

4.1. Immediacy: It is much easier and less time consuming to publish on the web than in the traditional print media. The publishing process for the print media involves several unavoidable steps before it is distributed to the audience. But with online newspapers, once information is available in soft copy, it can be loaded onto a newspaper website within a few seconds. Statements by leaders, politicians or public figures could be on the web even before they finish speaking and reactions to the statement could be coming in. The online newspaper does not have the distribution problem of the print (hard copy).

4.2. Permanency: Although we can re-read stories in printed newspapers on magazines, we are unlikely unable to read every print publication we get. Even if we were minded to try it, space limitation will eventually overwhelm us. With the web however, online newspaper materials can remain in place and be accessible as long as the web server and the electronic storage space exist.

4.3. Capacity: The traditional media (printed newspapers) are limited by space and time. This is not so with newspapers on the web (online newspaper), because the web erases this problem with its ability to keep and show large and huge amount of text and image materials. Can even set up a forum so that visitors or readers can react to the event, see the reactions of others and carry out discussion about those reactions online. The web newspapers and magazines have the potential to update news, showbiz and any other pages simultaneously and repeatedly gritty details on pop stars. A single news-site can post dozens of different updates on stories every few minutes. Immediacy super-changed by such flexibility is a potent tool, particularly for breaking news. Nigeria's online newspapers/magazines contain information on local issues, politics, events, celebrations, people and business, accommodation, shopping, bargain weather, holidays, vacations, resorts, real estate, property together with finance, stock market and investment reports, theatre, movie, culture.

4.4. Interactivity: The technology of the web offers a level of interactivity between the producer (journalist or writer) and consumers (readers or visitors) that goes far beyond what other media are capable of. The wide variety of material on the site can offer readers many more choices than if they were reading a magazine or a printed newspaper. Linking to other material on other sites is another way in which visitors or readers can interact with what they are seeing. This audience driven consumption attitude allows the readers to interact with the journalist as well the information at other levels such as:

4.4.1. The Consumer interacting with the Journalist: The most obvious examples of these are the readers who e-mail journalists with their views on what has been written or to give further information. This level of fairness displays a high level of citizen journalism. In this strive; information of half standard is counterbalanced.

4.4.2. The Reader interacting with the Reader: The use of message board on websites allows readers to exchange views and information on the board. This can provide different textures and perspective to a story. It offers an opportunity whereby the reader remains inalienable to critique his and others' contributions.

4.4.3. The Reader can also become the Writer: As the online medium matures, some of the voices out there are becoming more authoritative and confident in making contribution to the main context. Eventually, the interactivity increases latitude in getting involved in online journalism.

4.4.4. Linkage: The traditional role of the journalist or printed newspapers is further challenged by the online capacity to link readers onto other sites. A newspaper could run a story about lack of funding for school repairs in its area. It might contain a news piece and several related features or fact files. The online version of the paper could offer all that but also link the reader to the website of the Local Education Authority, the relevant government department, the Teacher's Association examples NUT, political parties, etc. To some traditional reporters on the newspapers, referring the reader to the source of problem solver; acts as a professional suicide. However, linkage only changes the journalist's role, it does not destroy it.

\section{The Concept of Print Media Readership}

Individuals in The Nation print readership are examined as part of larger aggregates called readership. It is a sub-classification of audiences. Print- readership studies focus on primary readers; those who buy the publication and ask along readers; those who use the newspapers as second hand. The people who buy the product and what is read are not known. So, when talking about readership, it refers to those who do not necessarily buy but whom we hope read the print media product, Hiebert et al. [9]. Primary readership or pass along readership are important aspect of the print audience because every reader is a potential reactor to the messages. Readers of newspaper and magazines possess the same audience characteristics as earlier identified.

\section{The Concept of Online Readership}

With the advent of online journalism, online newspapers came to be given way for online readership. Online readership refers to the web audience of the publication considered as a group. The online readership 
pattern is based on non-linear consumption. When choosing the story that interest them, the reader can and do go from one story to another. When stories are carefully selected and presented as news items and posted on the web, bonded together by immediacy and audience relevance, it is possible that the readers will not read large amount of it. In other words, the consumption pattern of web content is driven by the audience not by the provider. This suggests a need to re-think the traditional story telling process in deconstructing and reconstructing it for an online audience and their non-linear consumption pattern.

\section{Theoretical Framework}

It is the preposition of this researcher that the wider and more diversified group engages in reading, the better and all embracing is a developmental standard as no knowledge is wasteful. Also, the more information one is exposed to, the better the chances of proper selection and discrimination from the available news contents. Thus, a well informed or educated person should explore innumerable avenues of knowledge acquisition, and then, only from the abundance at his disposal can a reasonable choice be made about what is deemed acceptable or rejectable. Only a well informed mind can competently make a sound and impeccable judgment. Based on the above preposition, therefore, the theories relied on in this study are the 'Uses and Gratification' and 'Media Dependency' Theories:

\subsection{Uses and Gratification Theory}

According to Mc-Quail [10] the Uses and Gratification Theory which originated in the 1970s was a reaction to traditional mass communication emphasizing the sender and the message. The theory attempts to explain the uses and function of the mass media for individuals, group and society in general. It is of the view that The Nation does not do things to people; rather, people do things with The Nation. In other words, the influence of The Nation is limited to what people allow it to be. It stresses that people make use of The Nation for their specific needs. This approach is mostly concerned with what people do with the mass media, how The Nation satisfy these needs and wants, the part made by The Nation in our education, politics, and culture and how can people utilize The Nation to their advantage.

The Uses and Gratification Theory rest on several assumptions, one of which is that; audience being active seek out specific types of media content to satisfy their needs and interests, and articulate enough to verbalize it, though positive point of the theory is that it focuses attention on the individual in the mass communication process. However, it is not without some criticism which includes that; it does not consider the power of media and it is more audience-centered.

\subsection{Media Dependency Theory}

Equally thought as being relevant to this study is the Media Dependency Theory proposed by BallRokeach and De-Fleur [11] which states that "the more dependent an individual is on the media for having his or her needs fulfilled, the more important the media will be to that person". The Media Dependency Theory is related to the Uses and Gratification Theory as well as ties into the Agenda Setting Theory. People use the media for many reasons; information, entertainment, and Para-social relationships are just a few of them.

The Media Dependency Theory says the more a person becomes dependent on The Nation to fulfill his needs, The Nation will become more important to that individual. The Nation will also have much more influence and power over that individual hence; it is easier to set the agenda for such individuals. Generally based on the two theories above, one would state that The Nation will be used more when the existing motives to use the medium leads to more satisfaction. There are many other theories relevant to this study but in the scope of this research, the researcher shall limit his focus to the above mentioned ones.

\section{Review of Empirical Studies}

There was great accessibility of this study to "the Use of Internet Resource by Students of Federal University of Technology, Minna - Nigeria," Madu [12]. The result established a relationship that university students from a different varsity spent more time on internet resources such as World Wide Web (www), Electronic mail (E-mail) and Discussion Groups (DGs). The most common way of allocating information for learning according to the students, is the E-mail. Based on findings from the study, it was recommended that the University authority and government should make access to internet readily available to the students, by encouraging private sector involvement and provision of broadband internet access.

Also closely related to the subject matter is "New Generation, New Media and Digital Divide: Ownership, Access and Usage of Social Media among Young People in Nigeria," Amobi, [13]. Today the internet has become a social mechanism, parading blogs, podcasts and social networks and these appear to be inextricably woven into young people's lives. Studies from 2000 to 2003 indicated that more than half of the 269 million new internet users were young people. However, information from traditional media and visits to social media websites revealed heavy usage of social media by Nigerian youths. 
Concurrently, another research was undertaken in "Limitations to the use of Information and Communication Technologies for Research in Nigerian University Libraries," Madu [14]. The study examined the problems that Nigerian university library users encounter in the use of ICT facilities for sourcing information for research. The result showed that inhibitors to the use of ICT facilities for research in our university libraries include: irregular power supply, lack of skilled library staff to assist users, frequent breakdown of equipment, difficulty of access, poor support of infrastructure, etc. It is recommended that university libraries and government should encourage public-private partnership to promote ICT implementation in the libraries, and to form consortia at various levels in order to share resources.

For the eradication of doubt, Cross River University of Technology is not just a fresh university, created in 2002; as a transition from one of the oldest and glorious Polytechnics in South Eastern Nigeria (The Polytechnic of Calabar, then fondly called POLYCAL). She has remarkably produced reputable expatriates in different facades of Engineering and Humanities. In this vein CRUTECH remains unique and admirable from the abundance of wealthy practical and theoretical backgrounds, there come an excruciating necessity to resist this monstrous decline in students' reading culture and brace-up an enviable mouthpiece through media students for the betterment of the entire institution and the society at large. By such prevailing standard, a Mass Communication student is expected to develop a sumptuous readership appetite towards various local and global news contents. Even-though, this digitalized age places a lot of indication that the hardcopy newspaper readership is changing and getting obsolete as students flee from the papers to the net or no news at all. What informed the researcher into this work was to find out the readership appreciation of news content in The Nation newspaper or online version by Mass Communication students of CRUTECH. To support this stated objective, the following research questions were considered and adequately addressed to guide the study:

1) To what extent does news content of The Nation attract Mass Communication students of CRUTECH, Calabar campus?

2) To what extent is the readership frequency of Mass Communication students of CRUTECH influenced in relation to The Nation newspaper or its online version?

\section{Methodology}

9.1. Research Design: The area of the study is the Cross River University of Technology (CRUTECH), but with particular focus on the students of the Department of Mass Communication, Calabar campus. The Calabar campus is situated at Ekpo Abasi Street, Calabar South Local Government Area, which is located at the Southern Senatorial District of Cross River State, in Nigeria. "Calabar South headquarters are in the town of Anantigha. It has an area of $264 \mathrm{~km}^{2}$ and a population of 191,630 at the 2006 census," [15]. The population covered by this study was students in the Department of Mass Communication. According to records obtained from the Principal Executive Officer to the Head of Department. The overall students' enrolment in this Department for the academic session was five hundred and ninety-three (593), from classes 100 to 400 levels. The sampled procedure adopted was the stratified random sampling method in the pre-test where 20 students forming $11 \%$ of 180 students were sampled individually by the researcher on which media they regularly used before the questionnaire was administered on them. A final sampled size of forty-five (45) respondents (comprising twenty-five ' 25 ' male and twenty ' 20 ' female students respectively) were drawn from each of the four (4) classes listed for the study. This brought the total sampled size for the study to one hundred and eighty (180), one hundred and fifty (150) were returned, while thirty (30) were invalid. The simple random sampling technique was used in selecting The Nation and its internet from other samples. In doing this, the 'hat and draw' method was used amongst twenty randomly selected students. This process involved written letters ' $\mathrm{N}$ ' and ' $\mathrm{Y}$ ' - against the hard and net titles on the same paper, representing No and Yes responses from the respondents concerning their views on the types of mass media used. These letters ' $\mathrm{N}$ ' and ' $\mathrm{Y}$ ' was folded as paper balls and put into a container for respondents (readers of print and net media) to pick, seeking for their opinion. In this process the researcher, was able to realize fourteen (14) YES forming 70\% of the twenty students in favour of The Nation against others. This method of selecting and sampling is in line with the unbiased assessment of Denga and Ali [16], who contended that it is one of the most appropriate and justifiable method of selecting from a population of the same characteristic variables and also doubling as a simple random sampling technique. 9.2. Validity of Instrument: To ensure the validity and reliability of instrument employed, the researcher toke steps to ensure simplicity, clarity, conciseness and full comprehension of the fourteen (14) questions posed by carrying out a preliminary test involving a selected five (5) respondents from each of the four classes under study. The questions were close-ended with $2-9$ options to pick from as to guide the respondents accordingly. The observations and comments of students' and lecturers' responses respectively gave useful hints for amendments to the questionnaires before finally administering to the wider population of the study. Thereafter, upon completion, these were retrieved for collation, computation and analyzed as the data. The analyzed data were then presented, discussed and final conclusion drawn. 
Research Questions

Table 1: Analysis of responses on news content that attracts respondent in The Nation (This analysis answers research question one)

\begin{tabular}{|c|c|c|c|}
\hline QUESTION & \multicolumn{2}{|c|}{ FREQUENCY } & PERCENTAGE \\
\hline $\begin{array}{l}\text { What attracts the respondent } \\
\text { to The Nation's hard and net? }\end{array}$ & Hardcopy & Net version & \\
\hline Editorial news (a) & 21 & 9 & 20 \\
\hline Features $\quad$ (b) & 10 & 4 & 9.3 \\
\hline Sports $\quad$ (c) & 16 & 9 & 16.7 \\
\hline Foreign news $\quad$ (d) & 5 & 7 & 8 \\
\hline Advertisements (e) & 8 & 6 & 9.3 \\
\hline Arts and culture (f) & 10 & 2 & 8 \\
\hline Cartoon $\quad(\mathrm{g})$ & 6 & 3 & 6 \\
\hline Social media $\quad(\mathrm{h})$ & - & 24 & 16 \\
\hline Non-reader & 5 & 5 & 6.7 \\
\hline \multicolumn{2}{|l|}{ Total } & & 100 \\
\hline
\end{tabular}

Source: field work, 19th May, 2013.

Table 1, answered research question one, the media content appeal was discovered to be $50.7 \%$ (from $\mathrm{a}, \mathrm{b}, \mathrm{c}, \mathrm{d}, \mathrm{e}, \mathrm{f}$ and $\mathrm{g}$ ) who read the editorials and other interesting features of The Nation, $42.7 \%$ ( $\mathrm{a}, \mathrm{b}, \mathrm{c}, \mathrm{d}, \mathrm{e}, \mathrm{f}, \mathrm{g}$ and $\mathrm{h}$ ) read more of the online version and $6.7 \%$ (from $\mathrm{i}$ ) were either readers of these media.

Table 2: Analysis of responses on readership frequency in The Nation newspaper and net version (This analysis answers research question two)

\begin{tabular}{|c|c|c|c|}
\hline QUESTION & HARDCOPY & NET VERSION & PERCENTAGE \\
\hline Very greatly (a) & 58 & 29 & 58 \\
\hline Greatly $\quad$ (b) & 10 & 15 & 16.7 \\
\hline Not greatly (c) & 15 & 13 & 18.7 \\
\hline
\end{tabular}

Source: field work, 23rd May, 2013.

Table 2, summarized the answer to research question two, by stating that the readership frequency for The Nation newspaper was $55.3 \%$ (from a, b and c), while that of the online was $38 \%$ (a, b, c). And $6.7 \%$ (d) of these students were non-readers of either The Nation or net version (resulted from poor reading culture, penury or disinterestedness).

Applied Questions

Table 3: Analysis of responses on sources of obtaining news from The Nation (hard and net versions)

\begin{tabular}{|c|c|c|}
\hline QUESTION & FREQUENCY & PERCENTAGE \\
\hline \multicolumn{3}{|l|}{ Where does the respondent get the Nation? } \\
\hline Coupon purchase & 0 & 0 \\
\hline Offices & 0 & 0 \\
\hline School library (hardcopy) & 50 & 33.3 \\
\hline Departmental resource room - hardcopy & 45 & 30 \\
\hline Online phone browsing & 25 & 16.7 \\
\hline Newsstands, free readership - hard copy & 20 & 13.3 \\
\hline Non-readers & 10 & 6.7 \\
\hline Total & 150 & 100 \\
\hline
\end{tabular}

Source: field work, 3rd June, 2013.

Table 3, presented $76.7 \%$ (from c, d, and f) respondents as reading hard-copy of The Nation newspaper, while $16.7 \%$ (from e) read the online version and $6.7 \%(\mathrm{~g})$ were non-readers of the two media.

Table 4: Analysis of responses on presence of computer internet compliant in school library and Departmental resource room

\begin{tabular}{|l|l|l|}
\hline QUESTION & FREQUENCY & PERCENTAGE \\
\hline $\begin{array}{l}\text { How often do you use the internet } \\
\text { facilities in these venues? }\end{array}$ & & \\
\hline School library & 0 & 0 \\
Departmental resource room & 0 & 0 \\
\hline Total & $\mathbf{0}$ & $\mathbf{1 0 0}$ \\
\hline
\end{tabular}

Source: field work, 23rd June, 2013. 
Table 4, indicated that the University never provided computer internet compliance for the students either at the school library or Departmental resource room.

Table 5: Analysis of responses on whether one writes for or reads MACOSA or Ivory magazine

\begin{tabular}{|l|l|l|}
\hline QUESTION & RESPONSES & PERCENTAGE \\
\hline $\begin{array}{l}\text { Do you write for or read the } \\
\text { Departmental news media? }\end{array}$ & & \\
\hline MACOSA press board & 138 & 92 \\
Ivory magazine & 12 & 8 \\
\hline Total & $\mathbf{1 5 0}$ & $\mathbf{1 0 0}$ \\
\hline
\end{tabular}

Source: field work, 26th June, 2013.

In Table 5, this sampled population was also rated as $100 \%$ influencing the content of their locally produced media, for their campus news. This was in the aspect of affecting their local news media, in one form or the other, enhancing both preparation and dissemination of information.

\section{Discussion of findings}

The presentation of Table 1 shows that $20 \%$ read more of editorial news, $9.3 \%$ read the features, while $16.7 \%$ read the sports news. Eight percent read the international news, $9.3 \%$ for advertisements. Eight percent went for the arts and culture, $6 \%$ read cartoons, while $16 \%$ were addicted to the social media. Tables 2 and 3 showed that at great frequency of $55.3 \%$ and $76.7 \%$ of the students' population sourced for hard copy news of The Nation newspaper from the school library, Departmental resource room and newsstands. And $16.7 \%$ (Table 3) read the online version from their phones with a frequency of 38\% (Table 2). And 6.7\% (Table 3) appeared as non-readers in neither hardcopy nor net version. The study also revealed that there was no accessible computer internet compliant for the students, see Table 4. In Table 5, the result tends to support the "uses and gratification theory" on the yearning of the media students as being practically influenced by this practice at $100 \%$.

\section{Challenging Opportunities in Hypothetical Journalism}

In the transformation stages from a mundane to a realistic setting, this study quantified its revelations, firstly in both the online and hardcopy news contents of The Nation as local or editorial, sports news and social media networking - as having more attention than other areas, creating a severe drop for the news content of feature, international, arts and cultural, and cartoon news appeals. In reality there is all likelihood that locally produced media organs were influenced by experiences gotten from the existing exposure to national media. Secondly, the unhealthy discoveries were that the "Mass Communication Students' Association" - MACOSA press board was located at the entrance of general office to the Head of Department. Thirdly, their editorial writing practice was fairly influenced by open mindedness to The Nation's news and their one month industrial attachment (internship practice) in The Nigerian Chronicle newspaper and Cross River Broadcasting stations (both radio and television - CRBC and CRTV) in Calabar Municipality, Cross River State. Professionally, it is advisable that this exercise should be expanded to accommodate a six month's programme, for effective intensive learning of its technicalities. Fourthly, the Departmental Ivory magazine and Campus Courier newspaper were produced once in a blue moon. Beside their seldom nature of publishing, these print media should be advised to be online. These were prevailing challenges that made it impossible to disseminate information across the boundary of Mass Communication Department as the proposed campus ecclesiasts.

From the empirical studies, it was established that Nigerians are often noticed to be adjusting in the quest of greener educational pastures. Parents and students from Nigeria are made to migrate to claim better learning opportunities in neigbouring African countries. These weird conditions have also affected chronic brain drains in the capacities of losing quality manpower and Federal Government Revenue Base (FGRB). This claim is buttressed by "the National Universities Commission (NUC), attributing the rush by Nigerians to study in Ghanaian's universities due to stability in the country's educational system, stating that the instability of Nigeria's universities' academic calendar, caused by incessant strikes had affected them taking the pride of Africa in terms of research and man-power development," [17] (The Punch, online). How can one imagine the immediate past strike of Academic Staff Union of Universities (ASUU) starting from July 1st, 2013 - January 2014, over socio-educational infrastructures in public universities and EARN allowances to lecturers. Unimaginably, wasted months of no academic activity, the Federal Government have been dragging feet, parents and children at locker-heads and some deranged students causing atrocities from idleness, robberies and prostitutions. In the midst of Nigeria's natural and economic opulence, who picks the blame, 'the Andrew(s)'? 


\section{Conclusion}

In the light of the various findings, it can be categorically stated that Nigerian students should be exposed to computer literacy at an early stage. The students of MACOSA's reliance on dependency theory were relative. Learned traditions and values were based on availability of the media in-terms of proximity and ad-hoc reading attitudes influenced uses and gratification theory and to some extent exposed vicissitudes of life on readership, coming from penury - depriving a few. Reorientation could also unscrew their options and provide useful guidelines for changed behaviour in the overall appraisal of editorial and global assessment of news. Furthermore, Mass communication students' craze for hardcopy information could influence their readily physical, practical assessments of evident of facts for projects, seminars and production documentations. Most, especially in a country, where power supply is not only epileptic but completely extinct, and CRUTECH maintains burgeoning budget on diesel. Light-out in the hostels and classrooms at exactly 10 p.m. every night. An unbearable situation, how does one then appreciate The Nation and other online readership attitudes, knowing that phones needed to be charged? The financially un-favoured students are permanently forced back into Stone Age period - what an incredible age. The state government and the institution have their own share of blame, in providing enabling environment and which will also check cultism, truancy, by mindfully occupied with academic assignments. Let's not lose sleep over the nexus in this matter; both hardcopy and online versions have rich news contents in enhancing the students' uses and gratification theory on presentation of news facts. The online version has more fluidic nature of roaming around various interesting media contents than being a traditionalist in static media assessments (print media approach). Henceforth, there was great need for a balanced popular reading culture as expected alongside the widening and nourishing of their thirst for knowledge which will of course breakdown walls of hypothesis and create an all embracing journalism practice as ought to be the requirements for a 21 st century campus journalism. A courteous journalistic knowledge will surely earn them a niche for effective practice in dissemination of information within and outside the campus in redirecting the mindset of appreciating media contents in their citizenry.

\section{Recommendations}

Based on the identified shortfalls which included; students' inaccessibility to the internet facilities at the school library and Departmental resource room, where internet interactivity was unguaranteed. Like the results in "Limitations to the use of Information and Communication Technologies for Research in Nigerian University Libraries." This study also employs both the state government and public spirited organisations to come to the aid of the Department of Mass Communication in providing internet connected facilities. Also the availability of assorted print media publications will afford the students a wider range of reading ability within and outside their jurisdictions; the researcher went further to recommend the following:

1) That the students who are non-readers should strive seriously to develop reading habits towards deliberately, purposeful and committed reading culture with a sense of uses and gratification traits in regards to print media content and fluidic (interactive) nature of the online version.

2) That MACOSA press should be afforded an opportunity of establishing a website or blogger where their publications will be online for more effective dissemination and interactivity. The students should read widely and extensively by giving equal attention to all news contents of newspapers, magazines and their online counterparts.

3) Obviously, the print media consultants should also bear in mind that the Mass Communication students are fleeing from hardcopies to online web pages, and that they should therefore endeavour to sharpen the contents of the print media in retaining students' attention to their pages.

4) Mass Communication students' internship practical practice should be properly gazetted in Industrial Training Fund (ITF) scheme as a six month programme against the ad-hoc one month attachment (in favour of professionalizing the students). The students should be better exposed to more challenging and digitally oriented backgrounds. They should be opportune to experience supersonic journalistic productions in media houses in Abuja, Akwa Ibom, Lagos, Port-Harcourt, Jos, Kaduna and Kano.

5) At the end, the copious knowledge of journalism gotten from the presence of rich media status is supposed to register propitious objectives in their campus journalism practice. On this strength, it is recommended that MACOSA press publications should be made online as regards to their more regular attitude of publishing. And efforts should be reawakened to improve upon the quantity, quality, regularity and volume of the Ivory magazine and Campus Courier newspaper, so that they might reach the length and breadth of the school - possibilities of covering other departments' interest, is sacrosanct. If these recommendations are adhered to, any half-measure or scaremongering journalism will be avoided. Thence, hypothetical journalism by Mass Communication students as 'Ali Babas' in campus journalism will herald the Aladdin's wonderful experiences. 


\section{Acknowledgements}

[1] In memory of Mr. Eno Itam Obono, Principal Executive Officer to the Head of Mass Communication Department, Faculty of Communication Technology, Cross River University of Technology, Calabar; Cross River State, Nigeria. (For students' records and statistics)

[2] Master Rowland Ndoma Brown, Field Research Assistant on field works from 19th May, 2013 - 26 th June, 2013.

[3] Andrew(s): A popular TV advert in Nigeria, where a Nigerian deserts his country for greener pastures, because he could not withstand her corrupt and distasteful political economy. (For purpose of clarity)

[4] The author: He was 2012 to 2013 Industrial Attachment Co-coordinator for Mass Communication Department, Faculty of Communication Technology, Cross River University of Technology, Calabar; Cross River State, Nigeria. (For information)

\section{References}

[1]. Harris, M. Introduction to Mass Communication: Media Literacy and Culture, 2nd ed. Stanley J. Baran (ed.) (Boston: McGraw-Hill Higher education. 2002), p. 9.

[2]. DailyPost.online:http://dailypost.com.ng/2013/05/09/mass-failure-reps-summon-jamb-registrar/May 9, 2013.

[3]. Punch online:http://www.punchng.com/education/a-dons-antidote-to-failure-in-public-exams/August 2, 2013.

[4]. Brown, Ndoma J. "Educational Trends on Principles of Aesthetics in Contemporary Nigerian Magazine Designs" in Journal of Contemporary Research. Francis Mogu ed. Beijing: Universal Academic Services. Vol. 8, issue 3, 2011, p. 199.

[5]. Itule, Bruce D. and Douglas A. Anderson. News Writing Reporting: for Today's Media, 7th ed. (Boston: McGraw Hill Co. 2008) p. 15.

[6]. Nwosu, Ikem. Basics of Newspaper Journalism: for Print Media Students and Professionals (Enugu: Afrika-Link Books. 2004), p. 139

[7]. Brown, Ndoma J., Edde M. Iji; Veronica E. Bassey-Duke, Offiong Okon and Cornelius Udo Ellah. "Cartoon as Voices for National Development: The Nigerian Experience", in Annals of Humanities and Development Studies, Francis Mogu ed. Beijing: Universal Academic services. 1. (2) 2010, p. 181

[8]. Etim, A. "Online Journalism" Unpublished Lecture Note, Department of Mass Communication, Cross River State University of Technology, 2009, pp. $13-15$.

[9]. Hiebert, R.E., D.F. Ungurait and T.W. Bohn. Mass Media IV. An Introduction to Modern Communication (New York: Longman. 1985), pp. $346-347$.

[10]. Mc-Quail, D. "With More Hand-sight: Conceptual Problems and Some Ways Forward for Media Use". Research Communication, 26 (4), 2001, pp. 337 - 350

[11]. Ball-Rokeach, S.J. and M. L. De-Fleur. “A Dependency Model of Mass Media Effects” in Communication Research, 3, 3-21. 1976. (Last updated: March 21, 2000)

[12]. Madu, E. C. "Use of the Internet by Students in Nigerian Universities: A Case Study of Federal University of Technology, Minna, Nigeria", in Annals of Humanities and Development Studies, Francis Mogu (ed.) Beijing: Universal Academic services. 1. (2) 2010, p. 78 .

[13]. Amobi, Ifeoma T. "New Generation, New Media and Digital Divide: Ownership, Access and Usage of Social Media among Young People in Nigeria" in Communication Review. Lagos: A Journal of the Department of Mass Communication, 4, (4) 2010, p. 23.

[14]. Madu E. C. "Limitations to the use of Information and Communication Technologies for Research in Nigerian University Libraries", in Annals of Humanities and Development Studies, Francis Mogu ed. Beijing: Universal Academic services. 1. (2) 2010, p. 85 .

[15]. Census: NIPOST. http://en.wikipedia.org/wiki/Calabar_South. Retrieved: 2009-10-20.

[16]. Denga, Daniel and Yusuf Ali. Research in Educational Studies (Calabar: University of Calabar Press, 2004$)$ pp. 32 - 33.

[17]. The Punch.online:http://www.punchng.com/education/why-nigerians-study-in-ghana-okojie/September 3, 2013. 